\title{
A mortality study of nickel/chromium platers
}

\author{
T SORAHAN, ${ }^{1}$ D C L BURGES, ${ }^{2}$ J A H WATERHOUSE ${ }^{1}$ \\ From the Cancer Epidemiology Research Unit, ${ }^{1}$ University of Birmingham, Edgbaston, Birmingham B15 2TH, \\ and Health and Safety Executive, ${ }^{2}$ West Midlands Area, Queensway, Birmingham B4 7NP, UK
}

ABSTRACT The mortality experienced by a cohort of 2689 nickel/chromium platers between 1946 岕 and 1983 has been investigated. All members of the study cohort had some period of chrome $\underset{\mathbb{D}}{\odot}$ exposed employment. Overall, compared with the general population of England and Wales, statistically significant differences relating to cancer were found for cancer of the stomach $(E=16 \cdot 2$, + $\mathrm{O}=25)$, primary cancer of the liver $(\mathrm{E}=0.8, \mathrm{O}=4)$, cancer of the nose and nasal cavities $(\mathrm{E}=0.3$, $\mathrm{O}=3)$, cancers of the lung and bronchus $(E=48 \cdot 1, O=72)$, and all cancers $(E=164 \cdot 2, O=213)$. CO Chrome bath workers are the more heavily exposed workers, and a striking difference in SMRs was found for lung cancer among men first employed as chrome bath workers $(S M R=199)$ and men first employed as other chrome workers $(S M R=101)$. The method of regression models in life $\rightarrow$ tables (RMLT) was used to compare the durations of chrome exposed employment of those dying from causes of interest with those of all matching survivors in the same year of follow up, while $\vec{\bullet}$ controlling for sex, and for year and age of starting employment. Significant positive associations $\stackrel{\infty}{\cup}^{\infty}$ were found only for cancers of the lung and bronchus and duration of chrome bath work. In this study exposure to nickel was shown not to be an important confounding exposure.

In 1979 a working group of the International Agency for Research on Cancer evaluated the carcinogenic risk of chromium and chromium compounds to man, and concluded, "there is sufficient evidence of respiratory carcinogenicity in men occupationally exposed during chromate production. ${ }^{12-4}$ Three epidemiological studies of chromium plating industries were evaluated but it was concluded that, "data on lung cancer risk in other chromium associated occupations ... are insufficient."

In 1983 Franchini et al published some initial findings of mortality experience among a cohort of Italian chrome platers. ${ }^{5}$ For cancer of the lung they observed three deaths compared with an expectation of 0.9 .

The present study analyses the mortality experience of a group of chrome platers. The principal hypothesis to be tested was as follows: is there an association between estimated occupational exposures experienced by this group of chrome platers and an increased risk of mortality from cancers of the respiratory system? Exposure to chromium was in the form of chromic acid mist (chromium oxide, $\mathrm{CrO}_{3}$, soluble in water, hexavalent chromium).

Accepted 16 June 1986

\section{Study material}

FACTORY: PROCESS AND CONDITIONS Chrome plating carried out at the factory was of the decorative type, with a thin layer of chromium $(0 \cdot 25-0 \cdot 80$ microns) applied to an underlying layer of $\Phi$ nickel (10-40 microns). This process gave a bright, attractive finish to bumpers, over-riders, door handles, and window winders for motor cars.

Chrome plating, a process of electro-deposition, uses a solution of chromic acid, with a trace of sul-

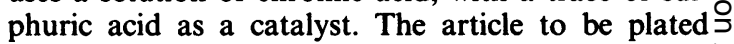
serves as a cathode, and when a DC electric current is $\frac{D}{2}$ passed through the electrolyte, chromium ions migrate to the cathode and are deposited on the arti- N cle. In addition water is dissociated into hydrogen and oxygen, these gases are released drawing some of the ${ }_{N}$ electrolyte with them, and a chromic acid mist is pro- $\mathrm{W}$ duced.

In the late 1940s and early 1950s the manual bathso in use in the factory were replaced by a semiautomatic $\Phi$ process, whereby operators moved jigs containing the $\stackrel{?}{?}$ components to be plated down a line of tracks con- $\frac{T}{T}$ taining various plating solutions. All the tanks con- $\frac{\text { Oे }}{\mathbb{D}}$

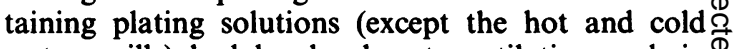
water swills) had local exhaust ventilation and, in $\triangle$ 
Table 1 Study population: vital status at 31 December 1983

\begin{tabular}{|c|c|c|c|c|}
\hline & \multicolumn{2}{|c|}{ Initial study population } & \multicolumn{2}{|c|}{ Final study population* } \\
\hline & No & $\%$ & No & $\%$ \\
\hline $\begin{array}{l}\text { Traced alive } \\
\text { Dead } \dagger \\
\text { Emigrated } \\
\text { Not traced }\end{array}$ & $\begin{array}{r}2013 \\
730 \\
155 \\
187\end{array}$ & $\begin{array}{r}65 \cdot 2 \\
23 \cdot 7 \\
5 \cdot 0 \\
6 \cdot 1\end{array}$ & $\begin{array}{r}1775 \\
715 \\
85 \\
114\end{array}$ & $\begin{array}{r}66 \cdot 0 \\
26 \cdot 6 \\
3 \cdot 2 \\
4 \cdot 2\end{array}$ \\
\hline Total & 3085 & $100 \cdot 0$ & 2689 & $100 \cdot 0$ \\
\hline
\end{tabular}

*Excludes 396 Asian workers.

†Includes deaths age 85 and over.

addition, the chromic acid baths had surface suppressants.

Some 60 occupational hygiene measurements were carried out before 1973, and although a few high values were recorded $\left(8 \cdot 0,1 \cdot 6,0.4 \mathrm{mg} / \mathrm{m}^{3}\right.$ chromic acid), the median value was "not detectable or trace." Levels of exposure, however, were such that some workers developed chrome ulcers (nasal and other) and asthma. In 1973 it became mandatory for levels of chromic acid over each bath to be measured fortnightly, the TLV for chromic acid and chromates as $\mathrm{CrO}_{3}$ was then $0.1 \mathrm{mg} / \mathrm{m}^{3}$. The vast majority of the measurements were entered in factory records as "less than $0.05 \mathrm{mg} / \mathrm{m}^{3}$." The TLV was reduced in 1977 to $0.05 \mathrm{mg} / \mathrm{m}^{3}$. Conditions in the plant were already improving in the early 1970s and chrome ulcers and asthma were no longer reported.

The scale of the operation was such that in the late 1960 s and early 1970 s some 80000 chromium plated bumpers and 40000 chromium plated overriders were manufactured each week.

\section{STUDY POPULATION}

Preliminary results of cancer mortality experienced by a cohort of chrome platers were reported by Waterhouse in $1975 .^{2}$ This study cohort was not, in fact, an entry cohort, rather it was one of "leavers," and the cohort definition did not include a minimum period of employment. The present analysis has been carried out on a redefined study cohort. Some workers included in the initial study are consequently excluded, and information for some workers not included in the initial study has recently been abstracted from the original personnel records.

The new study population comprised 3085 chrome workers who started chrome employment in a large

\section{Table 2 Job categories}

1 Chrome bath workers (chrome platers, nickel/chrome platers, service attendant, charge hand, panelman, plant attendant, pumpman, plater leading hand)

2 Chrome bath workers (jiggers and unjiggers)

3 Degreasers

Inspectors and viewers

Material handlers (general labourers)

Jig maintenance

Strippers

Zinc plating-passivation chrome plating and metal engineering plant in the Midlands (UK) between 1946 and 1975 and were employed for a minimum of six months. The personnel departments from which details of this study cohort were abstracted held records for some 50000 employees in all.

The Office of Population Censuses and Surveys (OPCS) provided information on the vital status of each individual on the closing date of the survey, 31 December 1983. (Details of workers for whom insufficient information was available for tracing by the OPCS were sent to the central offices of the Department of Health and Social Security for tracing using National Insurance numbers.) For those who had died, a death certificate was obtained with the underlying cause of death coded to the 8th revision of the ICD. Mortality was investigated for the period 1 January 1946 to 31 December 1983.

The new study population included 396 Asians (workers with Asian surnames) but subsequent analysis found overall mortality from all causes to be suspiciously low for this group of workers $(E=43.6$, $\mathrm{O}=15, \mathrm{SMR}=34$ ). They have, therefore, been excluded from the study, and the following results pertain to a final study population of 2689 chrome workers (1288 men, 1401 women). Table 1 shows the vital status of both study populations. Some 114 workers $(4 \cdot 2 \%)$ in the final study population remained untraced.

Detailed job histories (where available) - defined in terms of eight jobs involving chrome exposure (table 2)-were abstracted for those dying from causes of interest and for all available matching controls from the study population. Most jobs involving exposure to chrome also involved exposure to nickel in the form of nickel chloride and nickel sulphate.

The mortality experienced by a separate cohort of nickel platers (without exposures to chrome) from the same factory has been reported by Burges. ${ }^{6}$ No significant excess of lung cancer was found ( $<1$ year's exposure; $E=6.5, \quad O=9: \geqslant 1$ years exposure; $\mathrm{E}=1 \cdot 7, \mathrm{O}=1)$. By contrast, exposures associated with nickel refining are known to be associated with an increased risk of cancer of the nasal sinuses and cancer of the lung. ${ }^{7}$ 


\section{Methods}

The mortality experience of this cohort was compared with that which might have been expected to occur if rates of mortality for the general population of England and Wales had been operating on the study cohort, having due regard for the composition of the study cohort by age and sex and calendar year. Expected numbers of deaths were calculated using the Manyears computer program developed by Peto. Employees were censored on reaching their 85th birthday and no contributions are made to expected or observed numbers past this age.

The differences found between the observed mortality of an industrial cohort and its expected experience based on the rates of mortality for the general population, however, are clearly dependent on factors other than specific occupational exposures. Such factors will include selection effects within the workforce and the social class and regional composition of the study cohort. The method of regression models in life tables (RMLT) was therefore used to test the null hypothesis of no effect on mortality from occupational exposures associated with chrome plating (chrome exposure, for short). The method of RMLT was developed by $\mathrm{Cox},{ }^{8}$ who has given examples of its use in the analysis of clinical trials; the method has been used by Kneale et al in a cohort mortality study of radiation workers ${ }^{9}$ and by Sorahan and Waterhouse in a cohort mortality study of nickel

Table 3 Life table for subcohort*

\begin{tabular}{|c|c|c|}
\hline Year of follow up & No entering year & $\begin{array}{l}\text { No dying from causes } \\
\text { under investigationt }\end{array}$ \\
\hline $\begin{array}{l}1 \\
2 \\
3 \\
4 \\
4 \\
4 \\
19 \\
20 \\
21 \\
22 \\
23 \\
24 \\
25 \\
26 \\
27 \\
28 \\
29 \\
30 \\
31 \\
32 \\
33 \\
34 \\
35 \\
36 \\
37 \\
38\end{array}$ & $\begin{array}{l}72 \\
71 \\
69 \\
68 \\
- \\
64 \\
64 \\
64+ \\
63 \\
61 \\
60 \\
59 \\
58 \\
56 \\
55 \\
54 \\
53 \\
52 \\
52 \\
51 \\
51 \\
39 \\
32 \\
20 \\
14\end{array}$ & $\begin{array}{l}0 \\
0 \\
0 \\
0 \\
- \\
0 \\
0 \\
1 \\
1 \\
0 \\
0 \\
0 \\
0 \\
0 \\
1 \\
1 \\
0 \\
0 \\
0 \\
0 \\
0 \\
0 \\
1 \\
0 \\
0\end{array}$ \\
\hline
\end{tabular}

cadmium battery workers. ${ }^{10}$ It is Kneale's use of the method that is described here.

The method was used to compare the estimated chrome exposures of those who died in a given year of ? follow up with those of matching survivors in the? same year of follow up, while controlling for sex, yearo of starting chrome employment (1946-, 1951-, 1956-, $\frac{\bar{s}}{\overline{8}}$

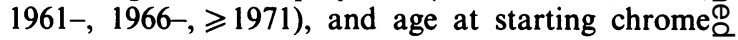
employment (15-, 20-, 25-, 30-, 35-, 40-, 45-, 50-, (ొ $\geqslant 55$ ). Periods of follow up for each individual are measured from the date of starting chrome employ-우 ment with the company.

The data were first divided into a large number of $\stackrel{\omega}{\sigma}$ subgroups $(n=108)$ by levels of the "controlling variables" mentioned above. For each subgroup, a 3 life table was constructed giving, for each year of fol- + low up, the total number entering the year and the $\rightarrow$ number dying from causes of interest. Detailed job N histories were then abstracted from the original per- 0 sonnel records for those dying from causes of interest $\mathrm{O}$ and for all matching survivors. Thus, for the sub- group shown in table 3 , detailed job histories were $\frac{D}{0}$ abstracted for the 64 employees who had survived to the beginning of the 21 st year of follow up. By $\overrightarrow{0}$ definition, all deaths occurring in later years of follow up, together with their matching survivors (controls), are included in this group of 64 employees. Note that those dying from causes of interest (cases) may also be matching survivors (controls) in earlier years of follow up.

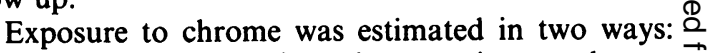
cumulative duration of employment in any chrome $\overrightarrow{\overrightarrow{0}}$ plating job (jobs 1-8, table 2) and cumulative 3 duration of employment in chrome bath work (jobs 1 层 and 2, table 2). The null hypothesis of no effect on mortality from the exposure is that the deaths in each $\stackrel{\bar{\Phi}}{-}$ year of follow up are a random sample of the entrants $\frac{\mathbb{D}}{3}$ to that year, and that the difference in the mean 0 cumulative exposures of these two categories should 3 . be zero. Cox proposed a broad class of regression 0 models for survival data. "Any biologically plausible $₹$ relationship between risk and exposure can be을 fitted," 11 and for these data we have tested the null $D$ hypothesis $(B=O)$ in the simple linear relation:

$$
\text { relative risk }=1+\mathrm{Bx}
$$

where $x$ is the cumulative exposure, $B$ is a constant, and the relation is assumed to hold over all subgroups and all years of follow up. More detailed descriptions $\omega$ of the method and the derivation of the appropriate test statistics have been published elsewhere. ${ }^{910}$

\section{Results}

SMR APPROACH

Table 4 shows observed and expected numbers of $\frac{\Phi}{\Phi}$ 


\section{A mortality study of nickel/chromium platers}

deaths for all causes, all cancers, and all causes other than cancer by years from starting chrome employment for men and women combined. There is no clear demonstration of a "healthy worker effect." The observed and expected numbers of deaths for specific sites of cancer and for other diseases among men, women, and the combined population are given in table 5. Compared with the general population, statistically significant excesses are shown among men for: cancer of the stomach $(\mathrm{E}=11 \cdot 3, \quad \mathrm{O}=21$, $\mathrm{p}<0.05$ ),

primary cancer of the liver $(E=0.6, O=4$, $\mathrm{p}<0.01$ ),

cancer of the nose and nasal cavities $(E=0 \cdot 2$, $\mathrm{O}=2, \mathrm{p}<0.05$ ),

cancer of the lung and bronchus $(E=40 \cdot 0, O=63$, $\mathrm{p}<0.001)$, all cancers $(E=96.9, O=142, p<0.001)$,

other diseases of the respiratory system $(E=54 \cdot 8$, $\mathrm{O}=72, \mathrm{p}<0.05$ )

and among men and women combined for:

cancer of the stomach $(E=16 \cdot 2, \quad O=25$, $\mathrm{p}<0.05$ ),

cancer of the liver $(E=0.8, O=4, p<0.05)$,

cancer of the nose and nasal cavities $(E=0.3$, $\mathrm{O}=3, \mathrm{p}<0.05$ ),

cancer of the lung and bronchus $(E=48 \cdot 1, O=72$, $\mathrm{p}<0.01$ ),

all cancers $(E=164 \cdot 2, O=213, p<0.001)$,

other diseases of the respiratory system $(E=76.4$, $\mathrm{O}=97, \mathrm{p}<0.05)$,

all causes $(E=607 \cdot 4, O=699, p<0.001)$.

The overall SMRs for all cancers among men and women are 147 and 105 respectively, whereas the

Table 4 Chrome platers, men and women combined, mortality 1946-83 by years from starting chrome employment

\begin{tabular}{|c|c|c|c|c|c|c|c|c|c|}
\hline \multirow{3}{*}{$\begin{array}{l}\text { Years from starting chrome } \\
\text { employment* }\end{array}$} & \multicolumn{9}{|c|}{ Cause of death } \\
\hline & \multicolumn{3}{|c|}{ All causes } & \multicolumn{3}{|c|}{ All cancers } & \multicolumn{3}{|c|}{ All causes other than cancer } \\
\hline & $E^{\dagger}$ & $O$ & $S M R$ & $E_{\dagger}^{\dagger}$ & $O$ & $S M R$ & $E \dagger$ & $O$ & $S M R$ \\
\hline $\begin{array}{l}0-4 \\
5-9 \\
10-14 \\
15-19 \\
\geqslant 20\end{array}$ & $\begin{array}{r}46 \cdot 4 \\
68 \cdot 8 \\
90 \cdot 0 \\
107 \cdot 3 \\
294 \cdot 8\end{array}$ & $\begin{array}{r}51 \\
81 \\
112 \\
117 \\
338\end{array}$ & $\begin{array}{l}110 \\
118 \\
124 \\
109 \\
114\end{array}$ & $\begin{array}{l}12.0 \\
18.8 \\
25.0 \\
29.7 \\
78.6\end{array}$ & $\begin{array}{r}16 \\
20 \\
40 \\
33 \\
104\end{array}$ & $\begin{array}{l}133 \\
106 \\
160 \\
111 \\
132\end{array}$ & $\begin{array}{r}34 \cdot 4 \\
50 \cdot 0 \\
65 \cdot 0 \\
77 \cdot 6 \\
216.2\end{array}$ & $\begin{array}{r}35 \\
61 \\
72 \\
84 \\
234\end{array}$ & $\begin{array}{l}102 \\
122 \\
111 \\
108 \\
108\end{array}$ \\
\hline Total & $607 \cdot 4$ & 699 & 115 & $164 \cdot 2$ & 213 & 130 & $443 \cdot 2$ & 486 & 110 \\
\hline
\end{tabular}

*Irrespective of how long any individual remains in the industry.

tCalculated on the basis of quinary-quinquennial rates of mortality for England and Wales 1946-80. Sum of expectations may not be fully consistent in the last digit due to rounding errors. Significance levels not shown.

Table 5 Chrome platers, cause-specific mortality 1946-83

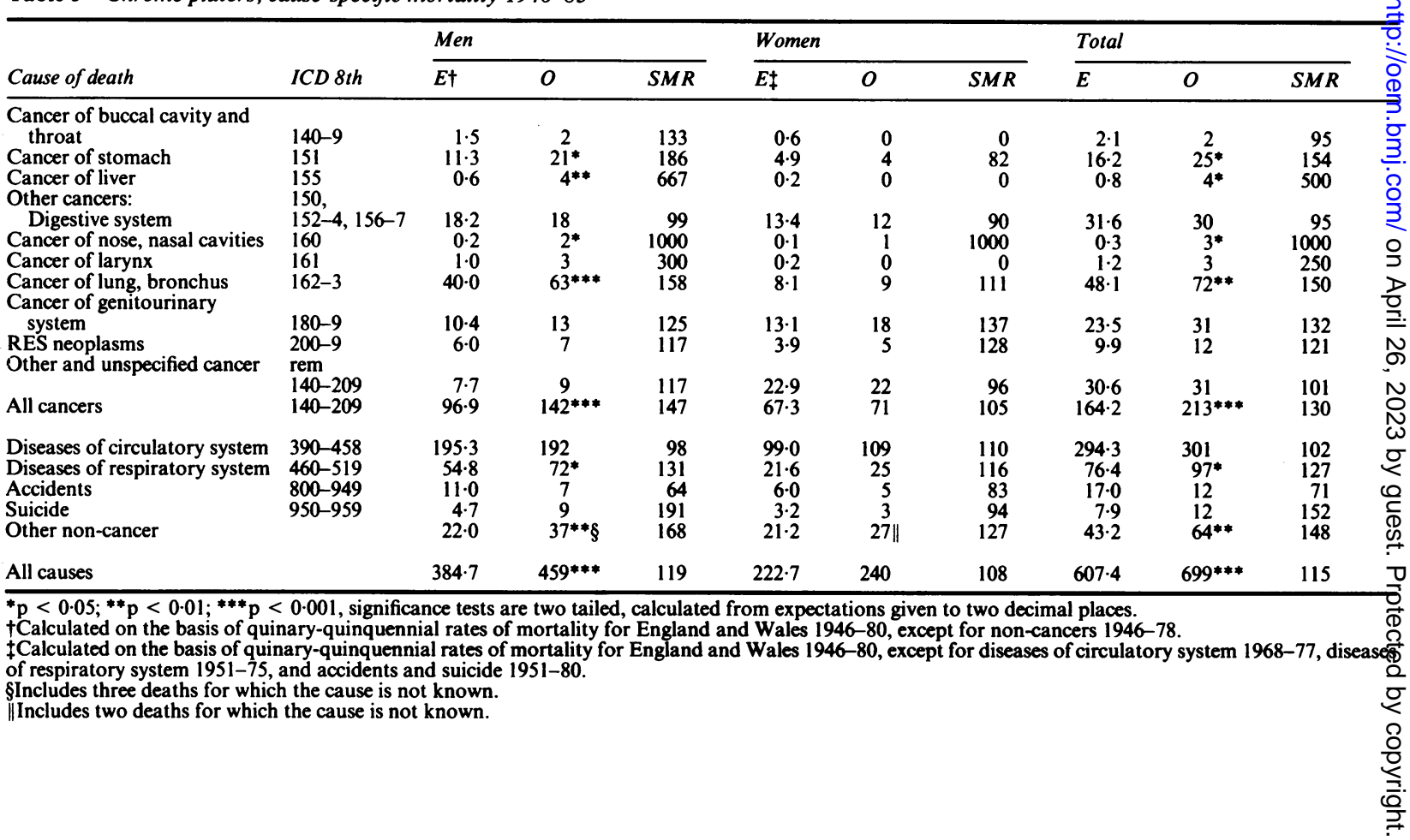


overall SMRs for all causes other than cancer are much closer, 110 and 109 respectively.

Of the four workers whose deaths had been ascribed to primary cancer of the liver, one (who died 18 years after first employment with 13 years "nickel only" work and two years chrome bath work) had not been registered as a patient with cancer at the Regional Cancer Registry and the postmortem report noted only that there were "deposits suggestive of hepatoma" in the liver, and a second had been registered with an unknown primary with no necropsy being carried out.

Of the three workers whose deaths had been ascribed to cancer of the nose, nasal cavities, and middle ear, one (who died 18 years after first employment with 13 years "nickel only" work and two years chrome bath work) had been otherwise registered at the Birmingham Regional Cancer Registry with a "poorly differentiated adenocarcinoma, mixed salivary tumour of the palate" (ICD 8: 145.1), and another (who died 11 years after first employment with one year of chrome bath work) had been regis- tered with "squamous cell carcinoma of left external 3 auditory meatus" (ICD 8: 173.2). (The third worker $\stackrel{\mathbb{0}}{\circ}$ who died 17 years after first employment had also had only one year of chrome bath work.)

In table 6 we show the observed and expected num-o bers of deaths by sex and type of first chrome employ-흘 ment (chrome bath or other chrome work). The most $\frac{\bar{c}}{\overline{7}}$ striking differences in the SMRs are shown for lung $\mathbb{\odot}$ cancer among men (chrome bath, SMR = 199; other chrome work, SMR = 101) and for lung cancer among men and women (chrome bath, SMR = 185; 0 other chrome work, SMR $=100$ ). The overall SMRs $\overrightarrow{\vec{H}}$ for all causes are similar among these two groups of ${ }_{\mathcal{O}}^{\omega}$ workers (chrome bath, SMR = 117; other chrome $\bigcirc$ work, SMR = 113).

Table 7 shows the observed and expected numbers of deaths from cancer of the lung and bronchus by type of first chrome employment (chrome bath ori other chrome work) and by years from first chromeo employment. Smooth trends in SMRs are not seen. 옹 The two highest SMRs are shown for chrome bathworkers 10-19 years from first chrome employment. $\frac{D}{0}$

Table 6 Chrome platers, cause-specific mortality 1946-83, by type of first chrome employment

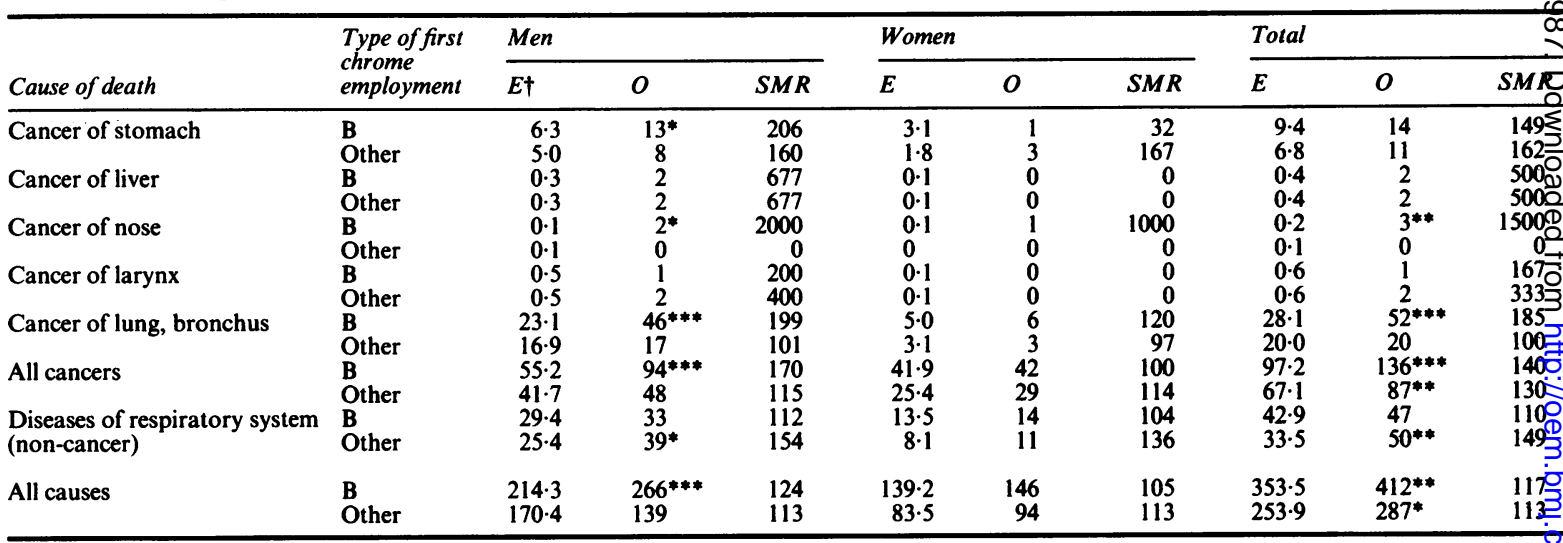

B = Chrome bath work, jobs 1 and 2 (table 2).

Other = Other chrome work, jobs 3-8 (table 2).

${ }^{*} \mathrm{p}<0.05 ;{ }^{* *} \mathrm{p}<0.01 ; * * * \mathrm{p}<0.001$.

† See footnotes table 5 .

Table 7 Chrome platers, men and women combined. Mortality from cancer of the lung and bronchus 1946-83 by type of first chrome employment and by years from starting chrome employment

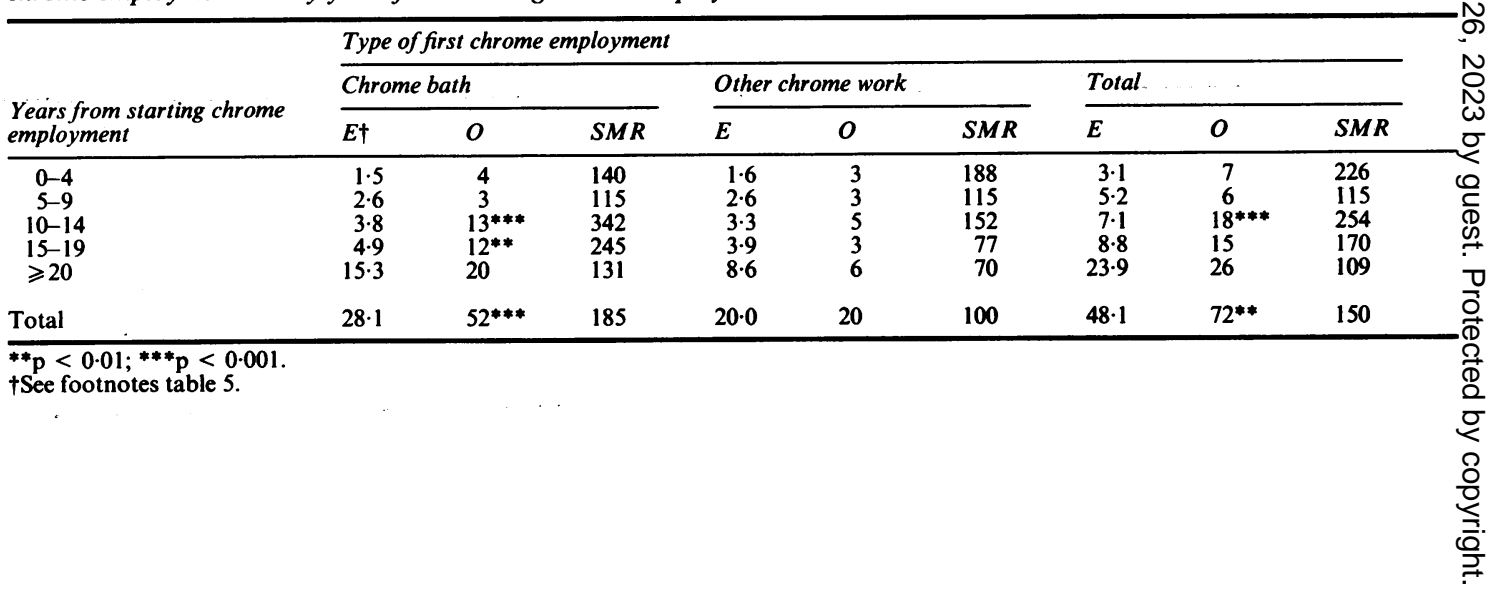


METHOD OF REGRESSION MODELS AND LIFE TABLES

The method of regression models and life tables was used to look for any evidence of association between the duration of chrome employment and the risk of mortality from (1) cancer of the liver, (2) cancer of the stomach, (3) cancer of the nose and larynx, and (4) cancer of the lung and bronchus. Two "exposure" estimates were considered: cumulative duration of any type of chrome work (jobs 1-8, table 2) and cumulative duration of chrome bath work (jobs 1,2 , table 2).

Detailed occupational histories were sought for a total of 1079 workers including 111 workers dying from the above causes (deaths occurring over the age of 85 are included). Of these 1079 employees, personnel records were unavailable for 179 and of the remaining 900,13 were subsequently found to be first employed pre-1946 and 52 to have had no period of chrome employment (see table 8).

The test statistics comparing the chrome employment of these who have died from the causes of death under investigation with those of all matching sur- vivors appear in table 9. Those employees who were subsequently found to have been first employed in chrome work pre-1946 or to have had no period of chrome employment are excluded from this table. There is no evidence of an association between duration of chrome employment and risk of mortality from cancer of the stomach, liver, or nose and larynx. Positive statistics, however, are obtained for cancer of the lung and bronchus (for chrome bath employment: $t=+1 \cdot 67, p=0 \cdot 10$ ). For cancer of the lung and bronchus, the median number of matching survivors per death (controls per case) was 21 .

The method readily allows an inspection of the contributions from subcohorts to the overall test statistic, and table 10 shows statistics by levels of controlling variables for cancer of the lung and bronchus. Positive statistics were obtained with both exposure estimates for the 43 deaths occurring among those starting chrome work between 1946 and 1955. Positive statistics are obtained for men (chrome bath employment, $\mathrm{t}=+1.92, \mathrm{p}<0.06$ ), whereas nonsignificant negative statistics are shown for women. Positive statistics were obtained for the three periods

Table 8 Derivation of data analysed by the method of regression models and life tables

\begin{tabular}{|c|c|c|c|c|c|}
\hline \multirow[b]{2}{*}{ Cause of interest } & \multicolumn{5}{|l|}{ No of deaths } \\
\hline & In SMR analysis* & $\begin{array}{l}\text { Available for } \\
\text { case-control onlyt }\end{array}$ & $\begin{array}{l}\text { Occupational histories } \\
\text { obtained } \$\end{array}$ & $\begin{array}{l}\text { Pre-46 chrome } \\
\text { employment\$ }\end{array}$ & $\begin{array}{l}\text { No chrome } \\
\text { employment } \|\end{array}$ \\
\hline $\begin{array}{l}\text { Cancer of stomach } \\
\text { Cancer of liver } \\
\text { Cancer of nose } \\
\text { Cancer of larynx } \\
\text { Cancer of lung }\end{array}$ & $\begin{array}{r}25 \\
4 \\
3 \\
3 \\
72\end{array}$ & $\begin{array}{r}25 \\
4 \\
3 \\
5 \\
73\end{array}$ & $\begin{array}{r}20 \\
4 \\
3 \\
5 \\
63\end{array}$ & $\begin{array}{l}0 \\
0 \\
0 \\
0 \\
2\end{array}$ & $\begin{array}{l}2 \\
0 \\
0 \\
0 \\
2\end{array}$ \\
\hline
\end{tabular}

*Censored at age 85 .

+No censoring - that is, includes deaths over age 85

tDetailed occupational histories sought for total of 1079 cases and matching controls, 900 were found.

$\$ 0$ f 900 cases and controls with detailed job histories, 13 were subsequently found to have started chrome employment in 1945 rather than in the period 1946 onwards.

\#Of 900 cases and controls with detailed job histories, 52 were subsequently found not to have had any period of chrome employment.

Table 9 Testing the null hypothesis of no effect from occupational exposures associated with chrome plating on causes of death under investigation by the method of RMLT†

\begin{tabular}{|c|c|c|c|c|c|c|c|c|}
\hline \multirow[b]{2}{*}{ Cause of death } & \multirow[b]{2}{*}{ ICD 8th } & \multirow[b]{2}{*}{$\begin{array}{l}\text { No of } \\
\text { deaths }\end{array}$} & \multicolumn{3}{|c|}{$\begin{array}{l}\text { Test factor } 1 \ddagger=\text { cumulative duration of } \\
\text { chrome work }\end{array}$} & \multicolumn{3}{|c|}{$\begin{array}{l}\text { Test factor } 2 \S=\text { cumulative duration of } \\
\text { chrome bath work }\end{array}$} \\
\hline & & & $\begin{array}{l}\text { Mean } \| \\
\text { exposure } \\
\text { deaths }\end{array}$ & $\begin{array}{l}\text { Mean } \\
\text { deviation } \\
\text { in exposure }\end{array}$ & $\begin{array}{l}\text { Test+† } \\
\text { statistic }\end{array}$ & $\begin{array}{l}\text { Mean } \| \\
\text { exposure } \\
\text { deaths }\end{array}$ & $\begin{array}{l}\text { Mean } \\
\text { deviation } \\
\text { in exposure }\end{array}$ & $\begin{array}{l}\text { Test†† } \\
\text { statistic }\end{array}$ \\
\hline \multirow{4}{*}{$\begin{array}{l}\text { Cancer of stomach } \\
\text { Cancer of liver } \\
\text { Cancer of } \\
\text { respiratory system: } \\
\text { Cancer of nose } \\
\text { and larynx } \\
\text { Cancer of lung } \\
\text { and bronchus }\end{array}$} & $\begin{array}{l}151 \\
155\end{array}$ & $\begin{array}{r}18 \\
4\end{array}$ & $\begin{array}{l}1.9 \\
2.5\end{array}$ & $\begin{array}{l}-1.2 \\
-1.4\end{array}$ & $\begin{array}{l}-1.14 \\
-0.61\end{array}$ & $\begin{array}{l}0.9 \\
0.7\end{array}$ & $\begin{array}{l}-0.9 \\
-1.6\end{array}$ & $\begin{array}{l}-0.96 \\
-0.76\end{array}$ \\
\hline & $160-3$ & 67 & $4 \cdot 0$ & +0.5 & +0.86 & $2 \cdot 4$ & +0.6 & $+1 \cdot 42$ \\
\hline & 160,161 & 8 & $2 \cdot 0$ & $-1 \cdot 4$ & -0.97 & 0.7 & -0.7 & -0.75 \\
\hline & 162,163 & 59 & $4 \cdot 2$ & +0.7 & +1.23 & $2 \cdot 6$ & +0.8 & $+1.67^{*}$ \\
\hline
\end{tabular}

* $p=0 \cdot 10$, two tailed test.

† Controlling for sex, year of starting chrome employment, and age at starting chrome employment. Those employees subsequently found to have started chrome employment pre-1946 or to have no period of chrome employment are excluded.

tExposure = cumulative duration of any type of chrome work (jobs 1-8, table 2).

Exposure = cumulative duration of chrome bath work (jobs 1-2, table 2).

In units of years of exposed employment.

IMean deviation in exposure between those dying from a particular cause and matching survivors, in units of years of exposed employment.

t†Asymptotically normally distributed. 
of follow up shown. The largest test statistics are obtained for the early period of follow up (first 10 years), although these statistics are based on only eight deaths.

Table 11 also shows test statistics comparing the chrome employment of those who have died from the causes of death under investigation with those of all matching survivors. Those employees who were subsequently found to have been employed in chrome work pre-1946 or to have had no period of chrome employment are included. Statistics similar to those shown in table 8 are obtained, except that the positive statistics shown for cancer of the lung and bronchus are increased, with that for duration of chrome bath work being significant at the $1 \%$ level $(\mathrm{t}=+2 \cdot 61)$.

There were 564 employees in the RMLT analysis with some period of chrome bath employment. It was known that 144 had either separate or simultaneous periods of nickel bath employment (some workers would have worked consecutively on lines of nickel baths and lines of chrome baths). The above RMLT analyses were repeated for "duration of nickel bath employment." Non-significant negative test statistics were obtained for all five causes of death.

One of the "shops" in the factory (H block) was known in particular to have been associated in the past with health problems such as chrome ulcers. A separate analysis was carried out to compare the risk of lung cancer in those ever employed in $\mathrm{H}$ block with those never so employed. Of the 63 observed deaths from cancer of the lung, 20 occurred among the $\mathrm{H}$ block employees and 43 occurred among the remainder (null hypothesis expectations were 17.6 and 45.4 respectively, by definition the sum of the observed deaths equals the sum of the expectations). This difference did not approach statistical significance.

Table 10 Testing the null hypothesis of no effect from occupational exposures associated with chrome plating on mortality from cancer of the lung and bronchus by the method of RMLT+: by levels of controlling variables

\begin{tabular}{|c|c|c|c|c|c|c|c|}
\hline \multirow[b]{2}{*}{ Subcohort } & \multirow[b]{2}{*}{$\begin{array}{l}\text { No of } \\
\text { deaths }\end{array}$} & \multicolumn{3}{|c|}{$\begin{array}{l}\text { Test factor } 1+=\text { cumulative duration of } \\
\text { chrome work }\end{array}$} & \multicolumn{3}{|c|}{$\begin{array}{l}\text { Test factor } 2 \S=\text { cumulative duration of } \\
\text { chrome bath work }\end{array}$} \\
\hline & & $\begin{array}{l}\text { Mean } \| \\
\text { exposure } \\
\text { deaths }\end{array}$ & $\begin{array}{l}\text { Mean } \mid \\
\text { deviation } \\
\text { in exposure }\end{array}$ & $\begin{array}{l}\text { Test }+\dagger \\
\text { statistic }\end{array}$ & $\begin{array}{l}\text { Mean } \| \\
\text { exposure } \\
\text { deaths }\end{array}$ & $\begin{array}{l}\text { Mean } \mid \\
\text { deviation } \\
\text { in exposure }\end{array}$ & $\begin{array}{l}\text { Test }+\dagger \\
\text { statistic }\end{array}$ \\
\hline \multicolumn{8}{|c|}{$\begin{array}{l}\text { Year of starting chrome } \\
\text { employment: }\end{array}$} \\
\hline $1946-$ & 17 & $4 \cdot 4$ & $+1 \cdot 1$ & +0.98 & $3 \cdot 9$ & $+1 \cdot 8$ & $+1 \cdot 81$ \\
\hline $1951-$ & 26 & $4 \cdot 7$ & +1.4 & $+1 \cdot 52$ & $2 \cdot 2$ & +0.5 & +0.73 \\
\hline 1956 & 8 & $3 \cdot 0$ & -1.4 & -0.80 & 1.9 & 0.0 & +0.01 \\
\hline $1961-$ & 4 & $4 \cdot 6$ & $-0 \cdot 2$ & -0.21 & 1.9 & +0.9 & $+1 \cdot 02$ \\
\hline $1966-$ & 4 & $2 \cdot 3$ & $-0 \cdot 1$ & -0.04 & 1.4 & -0.3 & $-0 \cdot 24$ \\
\hline$\geqslant 1971$ & 0 & - & $\ldots$ & - & - & - & - \\
\hline \multicolumn{8}{|l|}{ Sex: } \\
\hline Men & 51 & $4 \cdot 4$ & +0.9 & $+1 \cdot 36$ & $2 \cdot 9$ & $+1 \cdot 0$ & +1.92 \\
\hline Women & 8 & $3 \cdot 0$ & -0.4 & -0.41 & 0.8 & -0.7 & -0.86 \\
\hline \multicolumn{8}{|c|}{ By years of follow up: } \\
\hline $1-10$ & 8 & 3.9 & $+2 \cdot 1$ & $+3 \cdot 24^{* * *}$ & $2 \cdot 8$ & $+2 \cdot 0$ & $+3.98 * * *$ \\
\hline $11-20$ & 25 & $3 \cdot 7$ & +0.4 & +0.46 & $2 \cdot 0$ & +0.2 & +0.25 \\
\hline$\geqslant 21$ & 26 & $4 \cdot 8$ & +0.6 & +0.60 & $3 \cdot 0$ & $+1 \cdot 0$ & $+1 \cdot 20$ \\
\hline Total & 59 & $4 \cdot 2$ & $+0 \cdot 7$ & $+1 \cdot 23$ & $2 \cdot 6$ & +0.8 & +1.67 \\
\hline
\end{tabular}

***p $<0.001$.

$\dagger, \pm, \S, \|, \dagger+$ See table 9 .

Mean deviation in exposure between those dying from cancer of the lung and bronchus, and matching survivors, in units of years of exposed employment.

Table 11 Testing the null hypothesis of no effect from occupational exposures associated with chrome plating on causes of death under investigation by the method of RMLT†

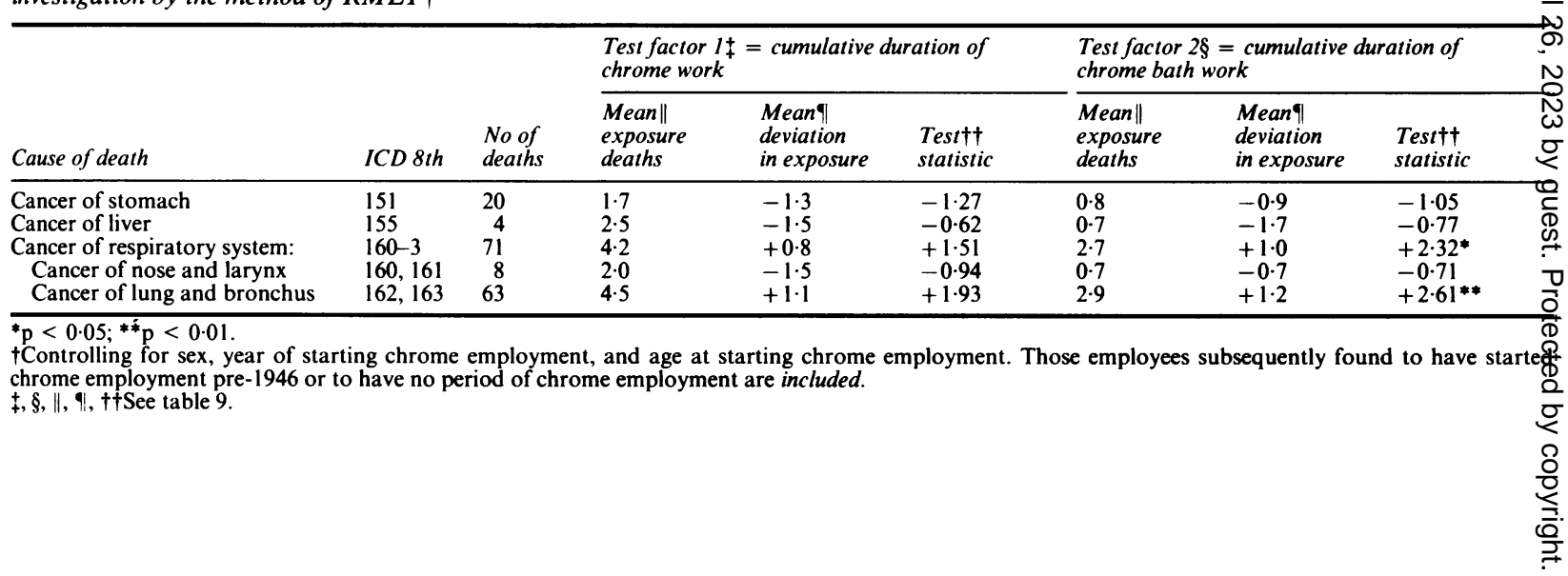




\section{Discussion}

The present study cohort was followed up from the date of starting chrome employment rather than the date of starting employment at the factory. For most individuals these two dates will be the same, for others they will not. This may account, at least in part, for the lack of evidence of a "healthy worker effect" in the data. Furthermore, because the work was dirty, unpopular, and physically undemanding, the magnitude of selection effects at time of entry into the industry may have been much smaller than that for many other industries.

In the general population there is a steep positive social class gradient for mortality from all cancers, cancer of the stomach, and cancers of the respiratory system. It is not surprising, therefore that, compared with the general population, this study cohort has an overall significant excess mortality from all cancers and cancers of the respiratory system. The key question to be answered is this: given that the mortality experience of the study cohort differs from that of the general population in several ways, is there any evidence that occupational factors are implicated in the observed pattern of mortality?

The difference in the SMRs for cancer of the lung and bronchus between male chrome bath workers (the more heavily exposed workers) and other male chrome workers is striking and is in itself suggestive of an occupational effect, even though for this particular analysis only one job code (first chrome job) was available. (An analysis of the detailed job histories used in the RMLT analysis indicated that only some $11 \%$ of workers had periods of both chrome bath and other chrome work.) Further, the results of the RMLT analysis, which are independent of those for the SMR analysis, showed an association between risk of mortality from cancer of the lung and bronchus and the duration of chrome bath employment.

In the RMLT analyses it was not possible to control for any "survivor population effect" in the data ${ }^{12}$ which would tend to produce negative test statistics. Also some workers who were acutely sensitive to chrome exposure would have been moved to other jobs. If such workers were also the more sensitive to any potential cancer risks their removal to other jobs would also tend to produce negative test statistics. These considerations, then, can only increase the importance to be attached to the positive statistics found for cancer of the lung and bronchus. Data on smoking habits were not available but there is no reason to believe that smoking habits would correlate with duration of chrome employment.

Although there was a significantly increased SMR for cancer of the nose and nasal cavities and all three deaths occurred among chrome bath workers, the
RMLT analysis found no evidence for an association between risk of mortality from cancer of the nose, nasal cavities, and larynx and either of the estimates of chrome exposure. (Two of the workers dying from cancer of the nose and nasal cavities had been employed for only one year as chrome bath workers. The other was employed for two years as a chrome bath worker.)

While there is no reason for believing that the degree of certainty concerning certified cause of death will be any less for the study cohort than for the general population, the four certified deaths from liver cancer are not all completely convincing. Further, although four is a small number of deaths for an RMLT analysis, no evidence for an association between risk of mortality and duration of chrome employment was found.

The RMLT analysis also failed to find any evidence of an association between the risk of mortality from cancer of the stomach and duration of chrome employment, and it seems likely that the raised mortality from cancer of the stomach among male chrome platers is due, at least in part, to social class differences.

Although many of those employed only as chrome bath platers would have some "vicinity" exposure to nickel, there is a negative finding for "duration of nickel bath employment" and cancer of the lung and bronchus. Probably some members of this study cohort suffered an increased risk of mortality from cancers of the lung and bronchus as a result of occupational exposures associated with nickel chromium plating, and the evidence from this study points to chromium rather than nickel plating.

We thank Dr R D Jones and Mr J T Hodgson-the two other members of the steering group for this project-for their advice and comments, Joyce Secker for the abstracting of complex job histories, David Peters for computing help and word processing, and the Colt Foundation for its generous financial support of these analyses.

We also thank the OPCS for tracing this population and we acknowledge the work of the late Dr Miles Kipling who initiated this study.

\section{References}

1 International Agency for Research on Cancer. Monographs on the evaluation of the carcinogenic risk of chemicals to humans. Vol 23. Some metals and metallic compounds. Lyon: IARC, 1980:205-323.

2 Waterhouse JAH. Cancer among chromium platers. Br J Cancer 1975;32:262. (Abstract.)

3 Royle $\mathbf{H}$. Toxicity of chromic acid in the chromium plating industry (1). Environ Res 1975;10:39-53.

4 Okubo T, Tsuchiya K. An epidemiological study on lung cancer among chromium plating workers. Keio J Med 1977;26:171-7. 
5 Franchini I, Magnani F, Mutti A. Mortality experience among chrome plating workers. Scand J Work Environ Health 1983;9:247-52.

6 Burges DCL. Mortality study of nickel platers. In: Brown SS, Sunderman FW, eds. Nickel toxicology. London: Academic Press, 1980:15-8.

7 International Agency for Research on Cancer. Monographs on the evaluation of carcinogenic risk of chemicals to man. Vol II. Cadmium, nickel, some epoxides, miscellaneous industrial chemicals, and general considerations on volatile anaesthetics. Lyon: IARC, 1976:75-112.

8 Cox DR. Regression models and life-tables. Journal of the Royal Statistical Society 1972;B34:187-220.
9 Kneale GW, Mancuso TF, Stewart AM. A cohort study of thi cancer risks from radiation to workers at Hanford. $\mathrm{Br} \mathrm{J} / \mathrm{g}$ Med 1981;38:156-66.

10 Sorahan T, Waterhouse JAH. Mortality study of nickel-cadmiu battery workers by the method of regression models in life tables. Br J Ind Med 1983;40:293-300.

11 Thomas DC. Statistical methods for measuring risks. In: Chiazze L, Lundin FE, Watkins D, eds. Methods and issues occupational and environmental epidemiology. New York: An Arbor Science, 1983:149-64.

12 Fox AJ, Collier PF. Low mortality rates in industrial cohose studies due to selection for work and survival in the industry. Br J Prev Soc Med 1976;30:225-30.

\section{Vancouver style}

All manuscripts submitted to the $\mathrm{Br} J$ Ind Med should conform to the uniform requirements for manuscripts submitted to biomedical journals (known as the Vancouver style)

The $\mathrm{Br} J$ Ind $\mathrm{Med}$, together with many other international biomedical journals, has agreed to accept articles prepared in accordance with the Vancouver style. The style (described in full in $\mathrm{Br}$ Med J, 24 February 1979, p 532) is intended to standardise requirements for authors.

References should be numbered consecutively in the order in which they are first mentioned in the text by Arabic numerals above the line on each occasion the reference is cited (Manson ${ }^{1}$ confirmed other reports $\left.{ }^{2-5} \ldots\right)$. In future references to papers submitted to the $\mathrm{Br} J$ Ind Med should include: the names of all authors if there are six or less or, if there are more, the first three followed by et al; the title of journal articles or book chapters; the titles of journals abbreviated according to the style of Index Medicus; and the first and final page numbers of the article or chapter.

Examples of common forms of references are:

${ }^{1}$ International Steering Committee of Medical Editors. Uniform requirements for manuscripts submitted to biomedical journals. Br Med J 1979;1:532-5.

${ }^{2}$ Soter NA, Wasserman SI, Austen KF. Cold urticaria: release into the circulation of histamine and eosino-phil chemotactic factor of anaphylaxis during cold challenge. $N$ Engl $J$ Med 1976;294:687-90.

${ }^{3}$ Weinstein L, Swartz MN. Pathogenic properties of invading micro-organisms. In: Sodeman WA Jr, Sodeman WA, eds. Pathologic physiology: mechanisms of disease. Philadelphia: W B Saunders, 1974:457-72. 